\title{
El «infatigable zapador»: La historia agraria de Josep Fontana
}

[...] este infatigable zapador, este roedor que fragmenta y divide el suelo, lo reparte $y$ corta una fanega de tierra en cien pedazos, convidado a este festín por una pequeña burguesía que hace de él a un tiempo su auxiliar y su presa [...]

Balzac, Los campesinos (1844)

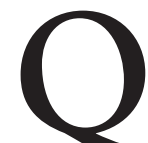
uizá resulte desconocida, sobre todo para los más jóvenes, la semblanza de Fontana como historiador agrario. En realidad pasaría casi lo mismo si cambiáramos el adjetivo agrario por económico o político. De modo que sus reflexiones sobre la historia agraria pueden estar dispersas en libros sobre el liberalismo del xIX o en los de metodología de la historia. Sería la mejor demostración de su acercamiento, como historiador marxista que siempre fue, a la historia total, aspiración con más predicamento ayer que hoy. Pese a estas prevenciones, la importancia de las publicaciones agraristas que figuran al final -más de una desconocida-invita a no olvidarlas. No hace falta extenderse en que el paso del tiempo ha fortalecido más unas hipótesis que otras.

Que las primeras investigaciones de J. Fontana tuvieran que ver con la historia agraria no es por casualidad. Según declaró alguna vez, lo que él deseaba inicialmente era trabajar sobre cómo afectaba la desamortización a los campesinos. Vicens Vives, que moriría en junio de 1960, le había recomendado a Pierre Vilar ${ }^{1}$. El tema del campesinado y la revo-

1. Este, después de aconsejarle seriedad y un estudio ordenado sobre el tema, le dijo: no es una ciencia fría la que queremos, pero es una ciencia (https://derehistoriographica.wordpress.com/2018/08/30/ josep-fontana-la-vocacion-de-la-historia-una-entrevista-desconocida-de-1998). En la comunicación 
lución liberal estuvo siempre presente, como poco hasta 2009; pero antes de indicar los grandes apartados en los que se puede dividir la obra agrarista de Josep Fontana conviene dar cuenta de su aportación al conocimiento de los ciclos económicos del siglo XIX. Lo hizo a menudo, por ejemplo, cuando escribió sobre la Revolución de 1868 y la crisis financiera que la precedió, pero no deja de ser singular que analizara, aunque con intensidad distinta, las dos grandes crisis que abren y cierran el siglo XIX. En efecto, en fechas muy tempranas (1960) publicó "La gran crisi bladera del segle XIX", un boceto de la crisis de fin de siglo: la competencia del grano ultramarino o ruso por la colonización de nuevas tierras, la revolución de los transportes, las consecuencias económicas para el mercado interior y políticas (Cánovas), temas todos en los que profundizaría Garrabou en su tesis doctoral.

Casi veinte años después analizó la crisis que se produjo al final de las guerras napoleónicas, que no se limitó a los cereales ni al ámbito europeo, sino que alcanzó unas dimensiones universales (1978). Son los años de la segunda revolución agrícola y de las grandes revueltas agrarias en Inglaterra. La crisis se transmitió a la economía española por tres canales: la caída de los precios de cereales importados, el colapso de las exportaciones agrarias españolas y los fenómenos deflacionarios, especialmente desde 1814 a 1820. Las consecuencias para las economías campesinas serían la disminución de las cargas diezmales, el aumento de la comercialización interior de cereales y el aumento de la producción agrícola. Como de costumbre, no se quedó en las cifras: la crisis fue un paso adelante para la agricultura comercializada en Inglaterra, mientras que para otros países como España contribuyó a gastar y destruir el viejo sistema que, sin estas influencias externas, tal vez hubiera podido durar más.

Estas primeras publicaciones se sustentan en una sólida investigación cuantitativa, igual que ocurre en un desconocidísimo artículo sobre la agricultura catalana (Fontana, 1962) en el que, aparte de criticar el mito de la propiedad repartida en Cataluña, se aportan datos y reflexiones sobre el mercado interior a fines de la autarquía.

\section{CAMBIO SOCIAL Y REFORMA AGRARIA LIBERAL}

Casi medio siglo separan La quiebra de la monarquía absoluta del libro póstumo que publicará la editorial Crítica, Capitalismo y democracia, 1756-1848: Como comenzó este en-

sobre la propiedad eclesiástica (por cierto, publicada a continuación de la de W. Kula) Fontana (1960b) trabajó sobre los libros de cuentas de los conventos catalanes y mallorquines para demostrar la decadencia económica antes de la desamortización y el aumento demográfico que supuso en los pueblos de alrededor la venta de los conventos en 1835 . 
gaño. Buena parte de ese tiempo lo dedicó a estudiar los orígenes del capitalismo, especialmente en España.Y lo hizo mediante el análisis del crecimiento económico, condicionado por la deuda y la Hacienda, y del poder político en el contexto de la coyuntura económica internacional. La crisis del Antiguo Régimen, como se observa en la bibliografía seleccionada, es el periodo más trabajado, en el que sobresale la obra cumbre $L a$ quiebra de la monarquía absoluta, (1814-1820) (1971). En ella, el modelo explicativo se articulaba en la triple crisis del comercio colonial, de la Hacienda y de las economías campesinas, un proceso lleno de rupturas y adaptaciones.

El colapso del comercio colonial en la economía española fue objeto de polémicas que aún no han remitido. Las conjeturas cuantitativas tendieron a minimizar los efectos macroeconómicos. Pero no cabe duda de que el cese del tráfico colonial afectó a las ramas más dinámicas de la economía española e hizo insostenible el déficit de la balanza de pagos en una coyuntura deflacionaria (Carreras \& Tafunell, 2010). Además, cambiar América por Europa no se pudo hacer automáticamente, dado el marco de inestabilidad institucional del primer tercio del siglo XIX. Aunque los flujos de productos agrarios se reorganizaron, la integración internacional de la agricultura española tendría que esperar a la segunda mitad del siglo XIX.

En cuanto a la Hacienda -si dejamos de lado la bancarrota de la Hacienda colonial que precedió a la quiebra de la Hacienda de la metrópoli ${ }^{2}$-, varios libros publicados por el Instituto de Estudios Fiscales convirtieron a Fontana en el mejor analista de la Hacienda pública. Integró la reforma tributaria en el estudio de la revolución liberal y al considerar la Hacienda como «alimento del Estado» correlacionó directamente crisis fiscal y política. El estudio hacendístico era un medio para comprender las contradicciones del crecimiento económico al final del Antiguo Régimen expuestas por Gonzalo de Luna en 1820: al paso que se han estancado la mayor parte de las tierras, se han hecho gravitar sobre los labradores las mayores cargas del Estado [...]. El resultado del cambio hacendístico no invitaba al optimismo, porque una cosa son los principios liberales y otra la práctica de la regresividad fiscal. Un reciente estudio, dedicado precisamente a J. Fontana, demuestra cómo las élites desplazaron la carga tributaria hacía los campesinos y consumidores, de modo que, a través de los impuestos y la deuda, continuó la transferencia de renta de los pecheros a los propietarios. Es decir, en cuestiones de Hacienda, la burguesía revolucionaria fue muy poco revolucionaria (Comín, 2018).

2. La crisis del Antiguo Régimen fue, en realidad, la del imperio español, Comín (2004:73). 
Y en tercer lugar, ¿qué pasó con las economías campesinas? Habría que distinguir entre dos temas bien distintos: el papel del campesinado y sus alianzas en la coyuntura de 1808-1820 y el debatido tema del cambio social en la reforma agraria liberal, en el que Fontana se convirtió en un referente inevitable y no siempre indiscutido ${ }^{3}$. Un repaso de sus publicaciones permite fijar dos características principales del cambio agrario decimonónico: a) la importancia del cambio desde abajo y no tanto de las medidas legales (la reforma silenciosa de la primera mitad del siglo XIX, cuando los campesinos acabaron con el diezmo y los derechos señoriales, fue más decisiva que la desamortización oficial); y b) el proceso adaptativo y a largo plazo. Se trata de estrategias que acomodan las reglas legales a las necesidades de quienes las dictan en nombre de todos y para todos. Ahora bien, en función de la resistencia con que tropiezan por quienes las ven como un instrumento de expropiación, se modifican y se adaptan a la práctica cotidiana. Las victorias pueden estar repartidas y no tiene por qué haber siempre expropiación de pequeños campesinos, que también son propietarios ${ }^{4}$.

Estos dos criterios permiten enfocar la cuestión agraria desde una perspectiva nada bipolar, de propietarios frente a desposeídos, muy lejos de la vía prusiana a la que se refirió inicialmente. Lo que se impuso fue la adopción de un programa «británico» de preferencia por la gran explotación debido al desconocimiento de otras fórmulas (o por la poca influencia de los González Alonso) y porque no se daban en España las condiciones que permitieron la movilización de los campesinos franceses. Justamente, el objetivo de quienes tutelaban aquella transición era evitar que la hez de la sociedad quisiese tomar la iniciativa de las reformas, como temía el Marqués de Miraflores ${ }^{5}$. Frente a lo que se ha dicho, los reformadores no se olvidaron de la dimensión social del problema agrario.

Cabría hacer otras consideraciones historiográficas para comprender la reiteración del juicio negativo que le merecía el término de burguesía revolucionaria (que coincide con el título del libro de Artola [1973]), pero no por eso Fontana tendría que ser considerado partidario de la tesis de la continuidad socioeconómica del Antiguo Régimen. Una definición no muy conocida resume el carácter de discontinuidad que le merecía aquella reforma agraria liberal:

3. Debatido una y otra vez, como ilustran diversos estados de la cuestión. El lector dispone de un amplísimo balance efectuado por RUIZ TORRES (2004). También a tener en cuenta: GARRABOU y RoBLEDO (1992); VilLARES (1999, 2004); CONGOST (2007).

4. Fontana (2003:158-165; 2009).

5. Fontana (1977:273; 1979a: 34-35; 2006: 120-121). 
No se puede negar la importancia de las transformaciones conseguidas por la revolución liberal o burguesa. El fin del privilegio eclesiástico, la modificación de las reglas de la propiedad-que tenían como consecuencia la eliminación de la vieja propiedad eclesiástica y la erosión de la comunidad campesina-y, sobre todo, la participación de los burgueses en la politica como electores y elegibles, que los convertirá en la fuerza social dominante, son ganancias suficientemente importantes como para que en su conjunto conformen un cambio social que ha necesitado una ruptura revolucionaria de las reglas de juego para poder realizarse (Fontana, 2003: 8) .

Paradójicamente, en la obra más divulgada se ofreció la versión más esquemática del cambio decimonónico. Las escasas páginas dedicadas al crecimiento agrario (Fontana, 2007a: 415-417) no reflejan los matices expuestos arriba sobre la proletarización, quizá por el interés en destacar el proceso de desigualdad al que conducían las medidas liberales. En todo caso las referencias, que son criticadas, sobre el despojo del campesinado (Ibid:183, 277) están relacionadas con la desamortización de comunales de Madoz, y justamente porque hubo despojo vino después el rescate de bienes comunales en la Segunda República ${ }^{7}$. No quiero cerrar este apartado sin resaltar cómo el historiador agrario del cambio decimonónico dispuso hace más de cuarenta años de un modelo explicativo de la revolución liberal que integraba la reforma agraria y la historia política-que él dominaba como pocos- con la evolución de la Hacienda.

\section{EL CAMPESINADO Y LA CRISIS DEL CRECIMIENTO AGRARIO}

Aunque la lupa necrológica pueda aumentar el valor de lo que se lee, hay otra labor en historia agraria no menos importante, como son los ensayos dedicados al campesinado (1997a, 1997b, 2001, 2003, 2010a). Se trata de reflexiones basadas en literatura secundaria que abren horizontes con propuestas metodológicas y orientaciones críticas. La información bibliográfica siempre al día de editoriales como Cambridge y Routledge, entre otras, que pocos de sus lectores podían disponer, se complementa con un conocimiento de publicaciones locales poco accesibles ${ }^{8}$.

6. Traducción y texto en redondilla de R. Robledo.

7. No soy hermeneuta ni árbitro de la polémica con J. Millán (2015) que el lector puede juzgar por sí mismo (Fontana, 2015: 243-260).

8. Por ejemplo, de la Asociación Provincial Cordobesa de Cronistas Oficiales para documentar que Pérez del Álamo era un gran contribuyente (FonTANA, 2010a). 
La mirada sobre el campesino, el «infatigable zapador», es una mirada desde la historia subalterna y muy diferente de la que ofrece la teoría modernizadora. Fenómenos demográficos como el crecimiento de la ilegitimidad rural se relacionan sobre todo con la disolución de la comunidad campesina en nombre de las exigencias de una agricultura comercializada, que no aceptaba los usos colectivos del suelo y las tierras comunales (Fontana, 2007b).

Las reflexiones críticas sobre la teoría de la modernización parten de dos supuestos metodológicos: a) la historia es un discurso sobre hegemonías (D. Rollison); y b) no hay una sola historia y conviene tener en cuenta los futuros olvidados objeto legítimo de profecía, en palabras de Machado.

Según el primer supuesto, la historia del campesinado habría sido en gran medida una invención urbana para resaltar los dones de la civilización y los males del «atraso». El dualismo campo-ciudad se habría construido sobre una falsa dicotomía. Asimismo, la tradición no sería algo inmóvil (de acuerdo con E. P. Thompson), sino un campo de cambio y de conflicto.

Consecuencia lógica del segundo supuesto era criticar las maravillas del high farming, por no reparar en los costes sociales de la criminalización de las prácticas consuetudinarias sobre sembrados y bosques y de la contrarrevolución agraria: los campesinos convertidos en mano de obra barata de la industria y transportes. Y por ocultar también la racionalidad de una evolución alternativa posible: la de una agricultura campesina que pudo haber subsistido y progresado en otra dirección. Los problemas de una concepción sesgada del progreso llegaron hasta Marx, incapaz, salvo en los años finales de su vida, de encajar el campesinado en la historia de la lucha de clases.

Fontana hacía suya la afirmación de Shanin, Los campesinos son una mixtificación, pues difícilmente podría aislarse a un grupo social distinto en países en que supone más del $80 \%-90 \%$ de la población. La historia agraria, por tanto, no podía dejar al margen los problemas de la desigualdad social, y de ahí que no escondiera las críticas al ecologismo cuando solo se ocupa de los bosques... Según su opinión, en el conocimiento de cuanto se refiere a la producción, la comercialización o las condiciones ecológicas había habido en la historia agraria un cierto olvido de su trama social.

Walter Benjamin fue uno de sus principales acreedores intelectuales y, por tanto, cultivó el sentido crítico ante los hechos del pasado, en las antípodas de Condorcet y de su creencia en que los progresos del hombre podrán seguir una marcha más o menos rápida, pero que nunca será retrógada. Esta perspectiva crítica, vertebradora de toda su investi- 
gación, tomó nuevo impulso al calor de la recesión económica abierta en 2007-2008.Varias de sus últimas publicaciones $(2010$ b, 2011, 2012), que no le impidieron escribir al mismo tiempo sobre la historia política o social de otros periodos, exploraron los límites del crecimiento agrario cuando la historia agraria española llevaba ya tiempo investigando sobre cuestiones medioambientales, dedicándose a ecologizar la historia (Soto \& LanaBerasain 2018: 14), enfoque ante el que marcó cierta distancia ${ }^{9}$. Fontana ofreció entonces un complejo marco explicativo poco frecuente: muy buena divulgación, con un alto nivel de información actualizada ${ }^{10}$ e integrando los problemas de la desigualdad económica y social, que Piketty había popularizado, con las variables políticas de las que el autor francés, según él, había prescindido.

Con este método, que no era más que su método habitual cercano a la historia total, sintetizó las causas y efectos de la crisis financiera de 2007-2008 como parte de otra crisis más global y más profunda, paralela en el tiempo, que no es atribuible al clima o a los errores de la política económica, sino que era manifestación de desequilibrios estructurales en la cadena alimentaria mundial. No estaríamos ya ante catástrofes humanas propias de países subdesarrollados, sino ante la reacción de pánico en los países desarrollados, que parecen haber despertado de súbito de los sueños de un crecimiento ilimitado. El agotamiento de la revolución verde en varios países había obligado a adoptar estrategias de apropiación de tierras en África o América Latina al margen de las poblaciones locales, convertidas en sujetos pasivos de la expropiación. Hay landgrabbing pero también water grabbing por las necesidades agrícolas, de consumo, y sobre todo de producción de energía, causante de miles de desplazados por la construcción de embalses.

Estos fenómenos de desposesión, incluidos los de la privatización del agua, se hacen en nombre del progreso económico global con el argumento de la supuesta mayor eficiencia de las grandes explotaciones agrarias. Fontana plantea la racionalidad de otras evoluciones alternativas posibles, como la de una agricultura campesina, auxiliada por formas diversas de coordinación y cooperación, que abandonen los modelos lineales de

9. No es el momento de interpretar esa distancia. Formado en la geografía histórica de los Annales (2007c), desconfiaba de historias del clima como la de Le Roy Ladurie o de alguna historia ambiental que juzgaba simple moda. Pero estaba muy lejos de cerrarse a las nuevas influencias, por lo que resumo a continuación y por sus recomendaciones de trabajos, entre otros, de Martínez Alier y de Garavaglia «quien señala la necesidad de introducir, al lado del estudio de «las relaciones entre las plantas, los animales, los hombres y el medio abiótico - es decir, los elementos climáticos, edáficos e hidrográficos", el de las relaciones que los hombres establecen entre sí como consecuencia de su participación en este proceso, incluyendo en ellas la tecnología y los saberes que los hombres han ido acumulando en sus complejas relaciones con la naturaleza» (1992: 77).

10. Véase las referencias de FonTANA (2011:1171-1175). La actualización bibliográfica posterior sobre la pobreza rural y las actividades de la vía campesina en El futuro es un país extraño (2013). 
evolución erigidos sobre la industrialización de fábrica y su necesario complemento de la gran explotación agrícola comercial.

Dos consideraciones cierran esta semblanza. La historia agraria española y el ambiente de discusión de la SEHA se han visto potenciados por libros como Historia agraria de la España contemporánea, que editaron Garrabou y otros autores, El pozo de todos los males, Sombras del progreso, y tantos otros títulos que no hicieron millonaria precisamente a la editorial Crítica. Como no solo de pan vive el hombre, habrá que citar a autores como M. Bloch, E. Hobsbawm, A. Soboul, R. Brenner, E. P.Thompson, E. A. Wrigley o A. W. Crosby, que sostuvieron a toda una generación en la tradición historiográfica del pensamiento marxista crítico en el que se desenvolvió Fontana. Fue mérito suyo -pero también de G. Pontón- que se abriera un caudal constante de publicaciones de afuera, bastante inaccesible para la mayoría de los historiadores, especialmente en los años 1970-1990. Por último, no hay mejor prueba de fidelidad a quien se merece justamente el apelativo de maestro que ser algo más que fieles devotos de su magisterio. Sirva de ejemplo el que varios de sus discípulos, influyentes historiadores, defendieran en los dos volúmenes de su Homenaje, e incluso en libros que él dirigía, opiniones distintas a las suyas...

Mi opinión personal es que Josep Fontana, con cuya muerte se dijo adiós a una forma de hacer historia, desapareció demasiado pronto como referente de la historia agraria española.

Ricardo Robledo

\section{PUBLICACIONES DE J. FONTANA SOBRE, O MUY RELACIONADAS CON, LA HISTORIA AGRARIA}

(1960a). La gran crisi bladera del segle XIX. Serra d'Or, (11), 21-22.

(1960). La gran propiedad agraria de los conventos españoles a comienzos del siglo XIX. Première Conférence internationale d'histoire économique: Stockholm 1960, (pp. 525530). Paris: Mouton.

(1962). Aspectos de la agricultura catalana. Información comercial española, ICE: Revista de economía, (342), 121-128.

(1971). La quiebra de la monarquía absoluta, 1814-1820: La crisis del Antiguo Régimen en España. Barcelona: Ariel.

(1973). Cambio económico y actitudes políticas en la España del siglo XIX. Barcelona: Ariel. 
(1977). Revolución liberal y reforma de la Hacienda. En J. FonTANA, La revolución liberal: Politica y hacienda en 1833-1845 (pp. 257-331). Madrid: Ministerio de Hacienda, Instituto de Estudios Fiscales.

(1978). La crisis agraria de comienzos del siglo xIX y sus repercusiones en España. Hacienda pública española, (55), 177-190.

(1979a). La crisis del Antiguo Régimen, 1808-1833. Barcelona: Crítica.

(1979b). Sobre revolución burguesa y autos de fe. Mientras Tanto, (1), 25-32.

(1980). Crisi camperola i revolta carlina. Recerques, (10), 7-16.

(1985). La desamortización de Mendizábal y sus antecedentes. En A. GARCíA SANZ y R. Garrabou (Eds.), Historia agraria de la España contemporánea. I: Cambio social y nuevas formes de propiedad (1800-1850) (pp. 219-244). Barcelona: Crítica.

(1988). La fi de l'Antic Règim i la industrialització (1787-1868): Història de Catalunya.

Vol v. Barcelona: Edicions 62.

(1992). Historia, espacio y recursos naturales: De la geografía humana a la "ecohistoria».

En J. Fontana, La historia después del fin de la historia: Reflexiones acerca de la situación actual de la ciencia histórica (pp. 65-78). Barcelona: Crítica.

(1997a). Campesinos, burgueses y revoluciones: Notas sobre algunos libros importantes:

Noticiario de historia agraria, (14), 215-219.

(1997b). Los campesinos en la historia: Reflexiones sobre un concepto y unos prejuicios.

Historia social, (28), 3-11.

(2001). El camperol: Una espècie en extinció? Una reflexió histórica. En R. ARNABAT

(Ed.), Els moviments socials al Penedès: Actes del II Seminari d'Història del Penedès (pp.

19-29).Vilafranca del Penedès: Institut d'Estudis Penedesencs.

(2003). La revolució liberal a Catalunya. Lleida: Eumo/Pagès.

(2006). De en medio del tiempo: la segunda restauración española, 1823-1834, Barcelona: Crítica.

(2007a). La época del liberalismo. En J. Fontana \& R. Villares (Drs.), Historia de España. Vol. 6, Barcelona/Madrid: Crítica/Marcial Pons

(2007b). Pecats camperols. En J. M. Delgado et al. (Eds.), Antoni Saumell i Soler. Miscel·lània in memoriam (pp. 69-77). Barcelona: Universitat Pompeu Fabra.

(2007c). El historiador y la geografía. En A. Cohen Amselem \& R. G. Peinado (Eds.), Historia, historiografía y ciencias sociales (pp. 87-100). Granada: Universidad de Granada.

(2009). Desamortización eclesiástica y reforma agraria liberal (España). En B. BoDINIER, R. Congost \& P. F. LunA (Eds.), De la Iglesia al Estado: Las desamortizaciones de bienes eclesiásticos en Francia, España y América Latina (pp. 205-222). Zaragoza: PUZ. (2010a). La trama social de la historia agraria. Revista de Estudios Maritimos y Sociales, Mar del Plata Argentina, (3), 108-114. 
(2010b). La crisis de 2006-2008: Unas reflexiones desde la perspectiva de la historia agraria. En R. RoBledo (Ed.), Sombras del progreso: Las huellas de la historia agraria. Homenaje a R. Garrabou (pp. 151-168). Barcelona: Crítica.

(2011). La otra cara de la crisis: La lucha por la tierra y los alimentos. En J. FonTANA, Por el bien del imperio: Una historia del mundo desde 1945 (pp. 949-963, 1171-1175). Barcelona: Pasado\&Presente.

(2012). Los usos de la Historia: Una reflexión sobre el agua. Vinculos de Historia, (1), 115125.

(2015). Respuesta al ensayo bibliográfico de Jesús Millán. Ayer, (98), 257-260.

\section{REFERENCIAS}

ARTOLA, M. (1973). La burguesía revolucionaria (1808-1874). Madrid: Alfaguara.

Comín, F. (2004). La metamorfosis de la Hacienda. En VV. AA., Fosep Fontana: Historia y proyecto social (pp. 31-101), Barcelona: Crítica.

Comín, F. (2018). Una «burguesía revolucionaria» poco revolucionaria en cuestiones de Hacienda (1808-1874). Áreas, (37), 79-91.

CARrERAS, A. \& TAFUnell, X. (2010). Historia económica de la España contemporánea (1789-2009). Barcelona: Crítica.

Congost, R. (2007). Tierras, leyes, historia: Estudios sobre «la gran obra de la propiedad». Barcelona: Crítica.

GARRABOU, R. \& ROBLEDO, R. (1992). Algunos temas de historia agraria de la España contemporánea. Bolletino bibliográfico, 1989-1990: Universitá degli Studi di Napoli, 4973.

Millán, J. (2015). La formación de la España contemporánea: El agotamiento explicativo del fracaso liberal. Ayer, (98), 243-256.

Ruiz ToRRES, P. (2004). La historiografía de la «cuestión agraria» en España. EnVV. AA., fosep Fontana: Historia y proyecto social. Barcelona: Crítica.

Soto, D. \& LANA-BERASAIN, J. M. (2018). La historia agraria contemporánea española en claroscuro. Sociedad de Estudios de Historia Agraria-Documentos de Trabajo, (1803).

VILLARES, R. (1999). La historia agraria de la España contemporánea: Interpretaciones y tendencias. En A. Reig TAPIA, J. L. DE LA GRANJA, R. MiRALles (Coords.). Tuñón de Lara y la historiografía española (pp. 219-244). Madrid: Siglo XXI.

VILLARES, R. (2004). El pasado que cambia: Reflexiones a propósito de la Revolución Liberal española. EnVV. AA., fosep Fontana: Historia y proyecto social (pp. 13-30), Barcelona: Crítica. 